\title{
KONTRAK TUKARAN MATAWANG ASING MELALUI INTERNET: SATU TINJAUAN HUKUM
}

\section{Alias Bin Azhar, Mohd Zaki Zainol and Mohd. Nizho Abdul Rahman}

\author{
Senior Lecturer, School of Law, College of Law, Government and International Studies,Universiti Utara Malaysia \\ (UUM), Kedah, Malaysia. E-mail: z.alias@uum.edu.my
}

Masters Candidate, Islamic Studies, College of Art and Sciences, Universiti Utara Malaysia (UUM), Kedah, Malaysia.E-mail: alusi003@yahoo.com

Senior Lecturer, School General Studies, College of Art and Sciences, Universiti Utara Malaysia (UUM), Kedah, Malaysia.

\begin{abstract}
Kontrak tukaran mata wang asing atau foreign exchange (forex) mula timbul apabila wujud urusniaga perdagangan antarabangsa yang melibatkan dua buah negara yang menggunakan matawang yang berbeza. Penilaian hukum dalam isu berkenaan perlu melalui kaedah pentafsiran dan pemahaman terhadap terma-terma yang digunapakai dalam kontrak tersebut. Terma-terma seperti leveraj, lindung nilai (hedging) dan swap dinilai secara tuntas berdasarkan modus operandi yang praktikal bagi membolehkan penilaian hukum dibuat secara tepat. Artikel ini membincangkan tentang isu-isu kontrak dan modus operandi urusniaga matawang asing serta aplikasinya dari aspek praktikal menggunakan internet. Perbincangan menjurus kepada penilaian hukum berdasarkan undang-undang transaksi Islam tentang bentuk kontrak ('akad) yang digunapakai, penggunaan lindung nilai dan leveraj dalam kontrak tukaran wang asing melalui internet.
\end{abstract}

Kata kunci : Kontrak, Tukaran Matawang Asing, Transaksi Islam, Leveraj, Muamalat

\begin{abstract}
Foreign currency exchange contracts or foreign exchange (forex) began to arise when there is an international trade transaction involves two countries using different currencies. The legal assessment of the said issue should apply methods of interpretation and understanding of the terms to be applied in the contract. Terms such as leverage, hedging (hedging) and swap are thoroughly evaluated based on a practical modus operandi allowing for the precise legal assessment. This article discusses the contractual issues and modus operandi of foreign currency transactions and its application from the practical aspects using the Internet. Discussion on the legal assessment is based on the Islamic law of transactions on applied type of contract ('akad), the use of hedging and leverage in foreign exchange contracts via the Internet.
\end{abstract}

Keywords: Contract, Foreign Exchange, Islamic Transaction, Leverage, Muamalat

\section{Pengenalan}

Wang adalah ciptaan yang terulung dalam sejarah manusia. Wang menjadi satu tarikan kepada manusia kerana ia boleh dikatakan sebagai kekuatan utama untuk manusia mendapatkan sesuatu keperluan dan kehendak setelah berakhirnya sistem barter. Ia juga memberikan pemiliknya daya beli untuk memenuhi setiap kehendaknya. Manakala dari segi peraturan perundangan pula, ianya merupakan alat bagi memenuhi kewajiban pemiliknya (Ahmad Hassan:2005; Sahir Hassan:1985). Keadaan ini berlaku disebabkan hampir keseluruhan urusan harian manusia yang dijalankan pada hari ini melibatkan penggunaan wang sama ada perniagaan itu berlaku secara domestik atau pun di pasaran antarabangsa.

Perniagaan domestik di sesebuah negara pula selalunya mudah dilaksanakan kerana ia hanya melibatkan penggunaan satu jenis matawang sahaja. Penggunaannya juga mudah dan tidak terdedah dengan risiko perubahan nilai matawang sama ada urusniaga dijalankan secara tunai atau kredit.(Wan Mansor:1993) Ia amat berbeza dengan urusniaga di pasaran antarabangsa. 
Urusniaga di pasaran antarabangsa pula selalunya melibatkan urusniaga di antara dua buah negara yang berbeza (A.J Dawson:1993). Secara tidak langsung ia melibatkan matawang negara masing-masing. Penggunaan matawang yang berbeza ini akhirnya telah menimbulkan beberapa isu persoalan dalam urusniaga matawang asing. Persoalan pertukaran matawang asing seterusnya menjadi lebih penting apabila ia juga turut melibatkan urusniaga melalui "atas talian" (on-line) yang pesat dan sekaligus telah membawa arus perubahan yang besar di dalam kehidupan manusia.

Nilai-nilai semasa merupakan asas yang kuat untuk menilai sesuatu hukum. Para fuqaha' menerima unsur ini sebagai salah satu daripada sumber hukum yang diistilahkan sebagai al-'Urf'. Di samping itu kaedah fiqh juga memperakui kewujudan unsur ini seperti kaedah al-'Adah Muhakkamah. Sejarah pembinaan hukum di dalam mazhab al-Syafie juga wujud Qaul Qadim ${ }^{2}$ dan Qaul Jadid ${ }^{3}$ Penilaian ini sudah tentu akan membawa kepada perubahan hukum agar ianya selaras dengan kehendak semasa. Perubahan ini pada hakikatnya tidak menafikan kemurnian syariah, tetapi membuktikan keanjalannya yang berfungsi di setiap masa dan keadaan.

\section{Sejarah Penggunaan Matawang}

Sejarah penggunaan matawang juga dikatakan telah melalui beberapa fasa. Bermula daripada empat khalifah terawal (632-661 M), Ummayyad (661-750 M), Abbasid (749-1258 M) dan Ottomans (1324$1691 \mathrm{M})$ dan revolusi industri (1880 hingga tercetusnya Perang Dunia (I) dan kadar pertukaran terapung 1973 hingga kini), matawang telah digunakan dengan meluas untuk tujuan pertukaran (seperti jual-beli barang dan perkhidmatan), simpan nilai (di institusi kewangan) juga untuk pelaburan (menghasilkan dividen). (Abd Ghafar, Azura: 2003)

Pertukaran matawang ini sebenarnya memiliki sejarah yang panjang sejak zaman pertukaran emas dan perak sehinggalah ke zaman matawang kertas.(M.Iqbal 2007: 18-26). Bermula dari situ, penggunaan pertukaran wang fiat ini semakin berkembang dengan adanya pasaran pertukaran asing. (Burhanuddin 2009: 4). Pada peringkat awal penggunaan wang fiat (wang kertas), ianya disandar sepenuhnya kepada emas, dan sesiapa juga yang memiliki wang kertas boleh menukarkannya dengan emas sebanyak yang tercatat pada kertas itu. Tetapi lama kelamaan, rizab emas negara semakin berkurangan dan wang kertas tidak lagi disandarkan kepada emas dengan sepenuhnya.

Selepas berakhirnya Perjanjian Bretton Woods pada 1971, wang kertas dunia tidak lagi disandarkan secara langsung kepada emas ( Imran Hosein 1997: 129-130) walaupun kemungkinan sesebuah negara masih lagi mempunyai rizab emasnya sendiri. Bermakna selepas berakhirnya penggunaan wang emas barulah munculnya penggunaan wang kertas dengan beberapa sistem pertukaran.

Wang juga mempunyai kekuatan belian dan ia mendapat kepercayaan umum. Ia juga dapat digunakan sebagai alat membayar hutang serta memenuhi keperluan-keperluan lain. Di samping itu, wang juga dianggap sesuatu yang diterima umum mengikut adat dan perundangan.(Roger Le Roy 1985:27) Dalam pasaran pertukaran matawang asing terdapat lapan (8) jenis matawang yang aktif dan utama seperti Dolar Amerika (USD), Pound British (GBP), Euro, franc Perancis, Franc Switzerland, Yen Jepun, Mark Jerman dan Euro Eropah.(Othman Yong 2002)

Atas sebab-sebab keperluan yang amat penting (daruriyyah) seperti keperluan di atas, maka para ulama' mengharuskan amalan urusniaga jual beli matawang. Walau bagaimanapun undang-undang muamalatnya mesti bersandarkan kepada prinsip-prinsip yang terkandung di dalam konsep al-Sarf ${ }^{4}$. Matawang juga tidak boleh dijadikan sebagai alat untuk melumpuhkan ekonomi sesebuah negara.(Azizi Che Seman 2005)

Perkembangan yang pesat dalam urusniaga pertukaran matawang asing ini telah mencapai kaedah transaksi yang lebih mudah dan $s p o t^{5}$, dan ia juga melibatkan urusniaga di kalangan peniaga-peniaga muslim. Situasi

\footnotetext{
${ }^{1}$ Al-Urf ialah kebiasaan atau adat budaya yang diterima pakai di dalam sesebuah masyarakat.

${ }^{2}$ Ijtihad atau fatwa yang dikeluarkan oleh Imam Syafie ketika beliau berada di Baghdad

${ }^{3}$ Ijtihad atau fatwa yang dikeluarkan oleh Imam Syafie ketika beliau berada di Mesir

${ }^{4}$ Al-Sarf:Akad penukaran atau transaksi matawang dengan matawang sama ada persamaan jenis atau berbeza jenis.

(Ibnu Abidin 1966)

${ }^{5}$ Spot: Transaksi matawang asing secara lani tanpa penangguhan.
} 
ini sudah pasti mengajak dunia ekonomi dan muamalat Islam untuk membuat satu kajian hukum semasa agar urusniaga ini tidak terkesan dengan amalan gharar $^{6}$, perjudian dan riba ${ }^{7}$

Maksud firman Allah:

"Hai orang-orang yang beriman, janganlah kamu memakan riba dengan berlipat ganda dan bertakwalah kepada Allah supaya kamu mendapat keberuntungan” (al-Imran: ayat 130).

\section{Tukaran Matawang Melalui Internet}

Kontrak yang digunakan dalam pertukaran matawang asing melalui elektronik adalah persoalan utama yang sering ditimbulkan apakah ianya secara bertulis, perbuatan ${ }^{(8)}$, berlafaz atau isyarat. Bagi menentukan bentuk kontrak yang digunakan maka perlu melihat apakah perantaraan yang digunakan dalam urusniaga melalui etransaksi ini sama ada ia melibatkan penggunaan komputer, telefon atau faks. Seperti yang diketahui, modus operandi bagi pertukaran matawang melalui internet melibatkan penggunaan komputer di mana kontrak digital berlaku dengan interaksi di antara komputer pembeli dengan komputer penjual. Setiap data yang dihantar melalui dua komputer tersebut dianalisis dan boleh dicetak. Berdasarkan kajian penulis, modus operandi yang digunakan jelas menunjukkan kontrak secara bertulis.

Kontrak secara bertulis ialah salah satu bentuk kontrak yang dibincangkan oleh ahli-ahli fiqh di samping tiga lagi kontrak iaitu kontak berlafaz, isyarat dan perbuatan (Ahmad Jazlan\& Zamzuri 2009). Ia merupakan salah satu cara melakukan kontrak jual beli dan dibenarkan oleh syarak. Kontrak bertulis juga boleh mengambarkan kehendak kedua-dua belah pihak yang berkontrak sama ada kedua-dua mampu berkata-kata atau salah seorang sahaja yang mampu berkata-kata. Begitu juga sama ada kedua-duanya berada dalam satu majlis atau mereka berdua berada di dua tempat yang berlainan (Ahmad Jazlan\& Zamzuri 2009).

Kontrak yang bertulis dari dua pihak yang tidak hadir (ghaib) samalah seperti kontrak yang dilafazkan oleh dua pihak yang hadir (al-Bali t.th:98). Maka berdasarkan dengan asas ini ahli perundangan Islam telah mengeluarkan satu kaedah am iaitu: (Ibn al-human t.th:79, Ibn Abidin 1995).

\section{الكِتَابُ كَالِخطَابِ \\ “Tulisan itu adalah sama dengan percakapan”}

Apa yang penting sekali dalam melaksanakan sebarang kontrak ialah lahirnya kehendak dari kedua belah pihak yang berkontrak. Kehendak merupakan perkara dalaman yang hanya boleh dizahirkan dengan petunjuk-petunjuk luaran yang terdiri daripada perkataan, perbuatan, tulisan dan isyarat (Syalabi, 1983). Kehendak adalah elemen yang sangat penting kerana ia merupakan asas kepada konsep rela-merelai seperti mana yang dirakam dalam al-Quran dalam surah al-Nissa,4:29:

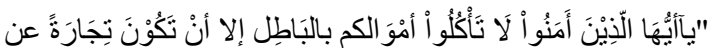

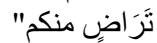

“Wahai orang-orang yang beriman, janganlah kamu makan harta orang lain dengan jalan yang batil, kecuali dengan perniagaan (jual beli) suka sama suka di antara kamu”,

Kontrak secara bertulis sebenarnya dibenarkan oleh syarak asalkan ia memenuhi dua syarat iaitu mustabinah wa marsumah. Maksud mustabinah ialah tulisan itu kekal di mana ia ditulis di atas satu benda yang dapat mengekalkannya seperti kertas, papan tulis, tanah, ukiran di atas kayu dan tidak sah ditulis di atas air dan udara. Manakala maksud marsumah pula ialah tulisan itu ditulis dengan cara tulisan yang biasa diamalkan oleh orang ramai seperti dalam urusan surat-menyurat hari ini memadai surat itu mengandungi nama orang dikirim surat itu kepadanya dan nama atau tandatangan pengirim di akhirnya (Ahmad Jazlan\&

\footnotetext{
${ }^{6}$ Gharar ditakrifkan sebagai ketidakpastian atau penipuan ketika melakukan akad jual beli. Ia merujuk sama ada kepada barangan yang tidak pasti wujud atau harga yang tidak pasti atau penipuan terhadap harga atau sifat barangan jualan. Islam menolak jual beli seperti ini kerana ia mempunyai unsur penipuan. Majlis Penasihat Syariah Suruhanjaya Sekuriti telah merumuskan bahawa gharar merupakan antara unsur negatif dalam sesuatu urus niaga

${ }^{7}$ Riba menurut imam Syafie ialah akad dengan nilai tambahan untuk sesuatu usaha tertentu yang tidak jelas jasanya menurut norma syariat saat akad, atau akibat penundaan serah terima kedua-dua barang yang ditukar atau salah satunya.(Hassan Ayob 2008:293)

${ }^{8}$ Juga disebut transaksi mu'thah seperti membeli minuman di dalam peti elektronik tanpa membeli dan penjual menyebut "Aku beli" dan "Aku jual".
} 
Zamzuri 2009).

Walau bagaimana pun hukum kontrak secara bertulis bukannya bermula semenjak penulisan surat itu, tetapi ianya di ambil kira sebaik sahaja surat itu sampai dan dibaca oleh penerima. Ini bermakna majlis kontrak bagi ijab (tawaran) yang dilakukan secara bertulis kepada orang ghaib (tidak hadir) hanya diambil kira apabila orang tersebut membaca tulisan itu dan jika dia membuat penerimaan dalam majlis itu juga, bermakna sempurnalah kontrak tersebut (al-Zarqa', 1998). Pembacaan surat tersebut untuk kali yang kedua ini menunjukkan berlakunya pengulangan ijab. (al-Sanhuri :t.t)

Berdasarkan analisa di atas, penulis dapat menyatakan bahawa bentuk kontrak yang berlaku dalam transaksi matawang asing melalui internet ialah secara kontrak bertulis. Hukumnya adalah harus seperti yang telah dibincangkan oleh ahli fiqh silam. Cuma mereka hanya menyentuh soal kontrak bertulis dengan kesesuaian zaman itu, contohnya seperti kontrak bertulis dengan surat menyurat. Namun apa yang di dapati pada zaman ini, kontrak bertulis yang terbentuk dalam urusan jual beli melalui internet bukan sahaja semata-mata kontrak berbentuk bertulis, bahkan kontrak itu itu boleh dibaca menerusi skrin computer dan dicetak.

\section{Sighah (Ucapan / isi kontrak)}

Sighah terbentuk dari dua lafaz yang berlainan. Kedua-dua lafaz ini keluar dari kehendak penjual dan pembeli. Bagi lafaz yang keluar daripada pihak penjual maka ia dipanggil ijab (penawaran) manakala lafaz penerimaan yang keluar daripada pembeli dipanggil qabul (penerimaan). Namun bagi mazhab Hanafi mereka berpendapat bahawa lafaz boleh berlaku dengan berbagai cara asalkan ia menunjukkan jual beli berlaku. Lafaz sighah boleh juga berlaku dalam perbuatan yang menunjukkan adanya ijab dan qabul.(alBuhuti 1982)

Siqhah juga menunjukkan sebagai tanda persetujuan dan keredaan mereka mengikat kontrak. Keredaan merupakan syarat utama syarat sah jual beli yang digambarkan oleh al-Quran melalui Kalam Allah yang bermaksud:

"Hai orang-orang yang beriman, janganlah kamu saling memakan harta sesamamu dengan jalan yang batil, kecuali dengan jalan perniagaan yang berlaku secara suka sama suka di antara kamu, dan janganlah kamu membunuh dirimu..Sesungguhnya Allah adalah Maha Penyayang kepadamu.’(al-Nissa':29)

Ayat di atas mejelaskan betapa perlunya sighah kerana ia adalah sebagai tanda seseorang untuk menyatakan kerelaaan dan persetujuan bersama dalam apa jua kontrak jual beli termasuk dalam urusan pertukaran perniagaan matawang asing melaui internet sekali pun.

Sighah pada kebiasaannya dilakukan secara lisan namun terdapat juga bentuk siqhah yang dilakukan selain daripada ucapan lisan. Syeikh Hassan Ayob(2008) mengatakan bahawa lafaz akad atau sighah kadang kala dilaksanakan secara langsung, dan kadangkala ia dilaksanakan melalui perantaraan alat moden seperti melalui telefon, faks dan lain-lain kecuali kontrak yang memerlukan kepada saksi seperti nikah. Beliau juga menjelaskan di antara contoh ijab secara soreh ialah seperti meletakkan iklan yang ditandatangani ke atasnya, atau penawaran pedagangan terhadap barang dagangannya kepada orang ramai dengan disertakan paparan harga yang jelas. Semua ini boleh dikategorikan sebagai penawaran yang jelas.

Memandangkan kontrak urusniaga internet melibatkan antara dua pihak yang kemungkinan besar tidak mengenali antara satu sama lain maka menjadi satu yang amat sukar bagi penjual mengenal pasti pembeli dan begitulah sebaliknya. Bagi membolehkan satu pihak mengetahui identiti satu pihak yang lain, maka setiap syarikat yang menyediakan platform urusniaga akan menyediakan satu borang pendaftaran elektronik pada laman sesawangnya untuk diisi oleh pembeli mengenai butiran peribadinya seperti nama, alamat suratmenyurat, alamat email dan nombor telefon.

\section{Lindung Nilai (Hedging)}

Konsep lindung nilai dan kepentingannya amat dititikberatkan dalam urusniaga dalam Islam. Ia merupakan sebagai proses mengurangkan risiko yang bakal dijangka dan persediaan bagi melindungi risiko tersebut.

Konsep perlindungan dari sebarang risiko dapat dilihat dari panduan al-Quran dengan firman Allah S.W.T 
Alias Bin Azhar, Mohd Zaki Zainol and Mohd. Nizho Abdul Rahman, 'Kontrak Tukaran Matawang Asing Melalui Internet: Satu Tinjauan Hukum', ISSN 2229-984X', UUMJLS, vol. 6, no. 1, 2015, pp. 137-146

seperti yang bermaksud:

“Wahai orang-orang yang beriman! Apabila kamu menjalankan sesuatu urusan dengan hutang piutang yang diberi tempoh hingga ke suatu masa yang tertentu maka hendaklah kamu menulis (hutang dan masa bayarannya) itu dan hendaklah seorang penulis di antara kamu menulisnya dengan adil (benar) dan janganlah seseorang penulis enggan menulis sebagaimana Allah telah mengajarkannya. Oleh itu, hendaklah dia menulis dan hendaklah orang yang berhutang itu merencanakan (isi surat hutang itu dengan jelas) dan hendaklah dia bertakwa kepada Allah Tuhannya dan janganlah dia mengurangkan sesuatu pun dari hutang itu. Kemudian jika orang yang berhutang itu bodoh atau lemah atau dia sendiri tidak dapat hendak merencanakan (isi itu), maka hendaklah direncanakan oleh walinya dengan adil (benar) dan hendaklah kamu mengadakan dua orang saksi lelaki dari kalangan kamu. Kemudian kalau tidak ada saksi dua orang lelaki, maka bolehlah, seorang lelaki dan dua orang perempuan dari orang-orang yang kamu setujui menjadi saksi, supaya jika yang seorang lupa dari saksi-saksi perempuan yang berdua itu maka dapat diingatkan oleh yang seorang lagi dan janganlah saksi-saksi itu enggan apabila mereka dipanggil menjadi saksi dan janganlah kamu jemu menulis perkara hutang yang bertempoh masanya itu, sama ada kecil atau besar jumlahnya. Yang demikian itu, lebih adil di sisi Allah dan lebih membetulkan (menguatkan) keterangan saksi dan juga lebih hampir kepada tidak menimbulkan keraguan kamu. Kecuali perkara itu mengenai perniagaan tunai yang kamu edarkan sesama sendiri, maka tiadalah salah jika kamu tidak menulisnya dan adakanlah saksi apabila kamu berjual beli dan janganlah mana-mana jurutulis dan saksi itu disusahkan dan kalau kamu melakukan (apa yang dilarang itu), maka sesungguhnya yang demikian adalah perbuatan fasik (derhaka) yang ada pada kamu. Oleh itu hendaklah kamu bertakwa kepada Allah dan (ingatlah), Allah (dengan keterangan ini) mengajar kamu dan Allah sentiasa Mengetahui akan tiap-tiap sesuatu. Dan jika kamu berada dalam musafir (lalu kamu berhutang atau memberi hutang yang bertempoh), sedang kamu tidak mendapati jurutulis, maka hendaklah diadakan barang gadaian untuk dipegang (oleh orang yang memberi hutang). Kemudian kalau yang memberi hutang percaya kepada yang berhutang (dengan tidak payah bersurat, saksi dan barang gadaian), maka hendaklah orang (yang berhutang) yang dipercayai itu menyempurnakan bayaran hutang yang diamanahkan kepadanya dan hendaklah dia bertakwa kepada Allah Tuhannya dan janganlah kamu (wahai orang-orang yang menjadi saksi) menyembunyikan perkara yang dipersaksikan itu dan sesiapa yang menyembunyikannya, maka sesungguhnya dia adalah orang yang berdosa hatinya dan (ingatlah), Allah sentiasa Mengetahui akan apa yang kamu kerjakan." (Surah Al Baqarah : 282 -283).

Berdasarkan daripada ayat al-Quran di atas, dapat kita fahami bahawa Allah S.W.T memerintahkan kita untuk merekodkan urusan hutang ataupun perniagaan yang telah dikontrak supaya tiada pihak yang dapat menafikannya dan menyebabkan kehilangan wang modal, selain perlu disaksikan oleh saksi-saksi yang adil.

Sekiranya urusan tersebut berlaku semasa perjalanan (safar), maka Allah membenarkan pemiutang mengambil cagaran daripada orang yang berhutang. Tindakan-tindakan tersebut disarankan oleh Allah Taala, selain kesedaran dan rasa tanggungjawab penghutang atau ahli perniagaan untuk menunaikan kewajipan masing-masing. Maka, dapat kita fahami daripadanya bahawa tawakkal dan kepercayaan terhadap pihak lain sahaja tidak memadai, tetapi langkah-langkah untuk mengelakkan penipuan atau kerugian yang tidak munasabah harus diambil.(Ashraf Wajdi :2009)

Risiko merupakan salah satu elemen terpenting yang harus dihadapi oleh setiap individu/syarikat ketika melaksanakan transaksi kewangan. Ini kerana keuntungan atau pulangan tidak akan dicapai tanpa berhadapan dengan risiko. Semakin tinggi risiko yang dihadapi maka semakin tinggi pulangan yang akan diperolehi, begitulah sebaliknya. Oleh kerana perkara yang akan datang adalah perkara yang tidak pasti, maka adalah penting bagi kita mengambil langkah untuk menghindari ketidakpastian jenis risiko tersebut. Ini selaras dengan prinsip asas perniagaan yang menyatakan "sesiapa menanggung kos dan kerugian, maka merekalah yang layak mendapat manfaat dan keuntungan jika ada”(Azlin Azlisa \& Dr Shofian: 2009).

\section{Ciri-Ciri Utama Lindung Nilai.}

Secara amnya ciri-ciri utama dalam lindung nilai boleh dikotegorikan kepada dua: (Asyraf Wajdi :2009)

(i) Sensitif terhadap harga: 
Alias Bin Azhar, Mohd Zaki Zainol and Mohd. Nizho Abdul Rahman, 'Kontrak Tukaran Matawang Asing Melalui Internet: Satu Tinjauan Hukum', ISSN 2229-984X', UUMJLS, vol. 6, no. 1, 2015, pp. 137-146

Ia dihitung berdasarkan perubahan dalam nilai aset atau kewajiban (liabiliti) untuk setiap perubahan dalam setiap peningkatan kadar faedah/bunga; nilai tersebut biasanya merupakan peratusan (percentage) perubahan nilai untuk setiap perubahan kadar faedah/bunga sebanyak 1 peratus.

(ii) Praktikal dari sudut ekonomi, terutamanya dari segi aspek kos:

Ini bermakna bahawa penggunaan instrumen lindung nilai harus efisyen dari segi kos, dengan mempertimbangkan bahawa kos lindung nilai tidak boleh melebihi jumlah pembiayaan yang perlu untuk menjamin tidak terjadinya kerugian.(Venkatesh dan Venkatesh, 1994).

Pada umumnya istilah hedging digunakan untuk menunjukkan suatu aktiviti bagi mengurangkan risiko dan menjadikannya neutral. (Sami al-Suwailem:2006). Ia juga ibarat suatu insuran untuk mengurangkan kos ke tahap yang paling minimum serta bertujuan melindungi kerugian aset daripada perubahan harga yang bertentangan.

Kesimpulannya, Islam amat menitikberatkan sebarang persediaan untuk melindungi dari sebarang bahaya dan risiko. Ciri-ciri perlindungan risiko ini sudah dijelaskan dalam al-Quran dan al-Sunah. Ia juga merangkumi segala aspek kehidupan termasuk perlindungan dari segi akidah, muamalat dan ekonomi. Dari sudut muamalat Islam pula sebarang perlindungan nilai mesti tidak tersasar dari maqasid syar'iyyah.

\section{Leveraj}

Urusniaga matawang asing melalui platform internet jelas menggunakan leveraj. Sarjana Islam berbeza pendapat dalam mengharuskan penggunaan leveraj. Sebahagian mengharuskan dan sebahagian lagi mengharamkan kerana menganggap leveraj adalah pinjaman. Kajian awal penulis mendapati konsep penggunaan leveraj yang telah disediakan oleh pihak broker secara talian internet tidak bercanggah dengan kehendak maqasid syar'iyyah. Perkhidmatan leveraj yang disediakan telah memudahkan urusniaga kepada pedagang bahkan ianya juga tiada sebarang unsur-unsur penindasan (gharar).

Leveraj dalam forex berdasarkan kajian penulis merupakan satu bentuk jaminan (pertolongan) sementara yang diberikan oleh broker untuk memasuki pasaran. Maka boleh dikatakan juga bahawa perkhidmatan leveraj yang disediakan ini adalah kontrak sementara antara peniaga forex dan broker selagi mana peniaga tersebut masih mempunyai ekuiti dalam akaun mereka. Bermakna perkhidmatan leveraj boleh digunakan oleh pedagang selagi mana pedagang memiliki sejumlah ekuiti dan menggunakan platform yang disediakan oleh broker tersebut sahaja. Pendapat yang mengatakan leveraj adalah pinjaman adalah tidak menepati kehendak urusniaga ini.

Bersandarkan kajian penulis, leveraj tidak menjadi halangan mengikut hukum syarak di dalam perlaksanaannya kerana ia merupakan satu keistimewaan atau kemudahan yang diberikan kepada pedagang. Penulis dapati kekeliruan para sarjana Islam dalam permasalahan ini disebabkan kekeliruan penggunaan istilah leveraj dan modus operandi leveraj tersebut. Oleh itu kaedah perundangan fiqh ada menyatakan :

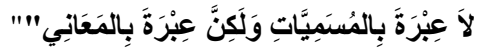

\section{Maksudnya: (Pengajaran (hukum) bukan diambil dari segi istilah sesuatu perkara bahkan pengajaran} (hukum) diambil dari cara perlaksanaannya).

\section{Pebezaan Leveraj Pinjaman dan Leveraj Forex}

Konsep leveraj dalam forex adalah amat berbeza daripada maksud leveraj dalam perniagaan khususnya dalam bab pinjaman. Al-Majma' al-Fiqh al-Islami, Rabitah al-Alam al-Islami telah mendefinisikan leverage sebagai:(Zamrey Razak :2010)

"Pembeli (pelanggan) membayar sebahagian kecil harga sesuatu yang ingin dibelinya iaitu dinamakan (margin) dan perantara (bank atau sebagainya) bertindak membayar baki atas asas pinjaman, di mana kontrak belian tersebut akan dikekalkan dengan perantara sebagai gadaian terhadap jumlah pinjaman”. 
Jadual dibawah dapat menunjukan perbezaan leveraj dalam forex dan pinjaman.

\begin{tabular}{|c|c|c|}
\hline Bil & Leveraj Dalam forex & Leveraj Dalam Pinjaman \\
\hline 1. & $\begin{array}{l}\text { Adalah satu pemberian atau jaminan } \\
\text { sementara dari broker dan diambil semula } \\
\text { oleh broker selepas lot niaga ditutup. }\end{array}$ & $\begin{array}{l}\text { Adalah satu bentuk pinjaman yang dimiliki oleh } \\
\text { peminjam dan mesti di bayar semula kepada pihak } \\
\text { peminjam. }\end{array}$ \\
\hline 2. & $\begin{array}{l}\text { Tidak dikenakan sebarang pembayaran kos } \\
\text { penggunaan. }\end{array}$ & $\begin{array}{l}\text { Dikenakan kos bayaran perkhidmatan jika } \\
\text { pembiayaan secara Islam. Jika di bank } \\
\text { konvensional peminjam akan dikenakan bayaran } \\
\text { bunga jika berlaku kelewatan pembayaran. }\end{array}$ \\
\hline 3. & $\begin{array}{l}\text { Kerugian yang ditanggung berdasarkan } \\
\text { modal yang didepositkan sahaja. Contoh } \\
\text { modal hanya RM1000, dan leveraj yang } \\
\text { diberikan sebanyak RM 100,000. Jika } \\
\text { berlaku sebarang kerugian, peniaga hanya } \\
\text { menanggung kerugian sebanyak RM1000 } \\
\text { sahaja. Bermakna, walau apapun leverage } \\
\text { yang pedagang perolehi dari pihak broker, } \\
\text { kerugian pedagang sama sekali tidak akan } \\
\text { berganda dari keseluruhan modal dan } \\
\text { leveraj yang yang dilaburkan. }\end{array}$ & $\begin{array}{l}\text { Kerugian yang ditanggung } \\
\text { keseluruhan pinjaman termasuk leveraj yang } \\
\text { diberikan. Contoh rumah bernilai RM100,000, } \\
\text { pembeli hanya membayar deposit RM10,000 dan } \\
\text { RM90,000 dipinjamkan dari bank. Jika berlaku } \\
\text { kerugian pembeli akan kerugian sebanyak } \\
\text { RM100,000 keseluruhannya, walaupun peminjam } \\
\text { hanya membayar deposit RM10,000 sahaja. }\end{array}$ \\
\hline 4. & Leveraj adalah hak milikan broker. & Leveraj adalah hak milikan peminjam. \\
\hline
\end{tabular}

Berdasarkan jadual di atas penulis dapati leveraj dalam urusniaga tukaran wang asing amat berbeza dengan leveraj dalam pinjaman. Sehubungan itu, penulis dapati leveraj amat hampir kepada salah satu kontrak dalam muamalat Islam iaitu kontrak tabarru' dan mu'awadah.

Mu'awadah mengikut istilah ahli fiqh ialah satu kontrak yang terbentuk berasaskan pertukaran obligasi secara timbal balik di antara dua pihak yang berkontrak (Shalabyy 1983, Mat Noor Mat Zain:2009) atau secara ringkasnya setiap kontrak yang mengandungi balasan daripada dua belah pihak (al-Dusuqi: t.t; alSawiy:1973)

Kontrak mu'awadah ini sebenarnya terbentuk berdasarkan pertukaran sesuatu hak. Sebahagian ulama fiqh membahagi kontrak kepada tiga bentuk iaitu; kontrak mu'awadah, kontrak tabarru' dan kontrak yang berunsur kontrak tabarru' pada peringkat permulaan dan mu'awadah pada peringkat akhirnya (al-Zarqa: 1967).

Kontrak mu'awadah merupakan kontrak yang terbentuk berasaskan pertukaran subjek kontrak secara timbal balik di antara pihak-pihak yang terlibat. Ia juga dibentuk berasaskan konsep saling tanggung menanggung obligasi di antara mereka, maka kemanfaatan dan kepentingan kontrak dapat diperolehi oleh kedua-dua belah pihak.

Sementara kontrak tabarru' pula didefinisikan sebagai suatu kontrak yang dibentuk atas dasar sumbangan (minhah) atau bantuan daripada salah satu pihak kepada satu pihak lain tanpa ada ganjaran (Mat Noor Mat Zain 2009). Menurut Mahmasaniy (1983) pula ialah kontrak yang manfaatnya kepada salah satu pihak yang berkontrak, tidak kepada satu pihak lagi.

Berdasarkan takrif di atas dapatlah di katakan bahawa kontrak tabarru' ini tidak mempunyai ganjaran atau balasan. Sebaliknya berlaku atas dasar belas kasihan dan sifat ingin menolong terhadap pihak kedua, di mana orang yang memberi tidak meminta balasan daripada pihak yang diberi.

Pendapat Mazhab Syafie dan Hanbali, kontrak seperti itu dikira mu'awadah pada keseluruhannya. Hukumnya penerima pemberian mesti memberi balasan yang disyaratkan dan dilaksanakan mengikut hukum kontrak mu'awadah dengan adanya hak shuf'ah dan khiyar, jaminan keselamatan barang hingga boleh diserahkan dan seumpamanya yang telah ditetapkan dalam jual beli ( Syarbini 1978, Mat Noor 2009). Hujah mereka ialah pensyaratan secara terus (langsung) telah membatalkan kontrak pemberian, kerana ianya syarat yang bersalahan dengan kehendak kontrak atau muqtada al-aqd (مقتضى العقد) (Wahba alZuhaily 1989) di mana matlamat sebenar pemberi hibah ialah untuk mendapatkan balasan. 
Modus operandi penggunaan leveraj dalam urusniaga tukaran wang asing hanya diberikan setelah peniaga ada equiti dalam akaun platform broker sahaja. Jaminan leveraj diberikan setelah persetujuan bersama antara peniaga dan syarikat broker. Maka selepas dianalisis data dan kedudukannya maka kontrak leveraj ini sebenarnya lebih hampir kepada kontrak mu'awadah.

Konrak mu'awadah tidak mutlak ini pada kebiasaannya berbentuk kontrak tabarru' pada peringkat permulaannya dan pelaksanaannya berakhir dengan kontrak mu'awadah. Bermakna semasa dalam awal pembentukan ia mengikut syarat-syarat kontrak tabarru' dan pada peringkat akhirnya ia mengikut hukum kontrak mu'awadah. Antara kontrak yang dikotegorikan dalam bahagian ini ialah pinjaman, hiwalah dan kafalah dengan arahan si berhutang, dan kontrak pemberian disyaratkan ada balasan. (al-Zarqa':1967, Madkur:1963, Wahbah al-Zuhaily 1989)

Konsep leveraj dalam urusniaga matawang asing di platform syarikat broker melalui internet sebenarnya bukanlah sama dengan konsep leveraj dalam pinjaman. Ia lebih hampir kepada kontrak ' $m u$ 'wadah tidak mutlak" di mana pemberian leveraj pada peringkat awal bersifat tabarru' iaitu pemberian jaminan (kafalah) memasuki pasaran dengan leveraj yang di sediakan tanpa syarat balasan.

Pada pandangan penulis kontrak ini diharuskan kerana ia bukanlah kontrak pinjaman yang bersyarat. Bahkan leveraj di sini lebih bersifat jaminan (kafalah) sementara kepada peniaga untuk memasuki pasaran dan diberikan dalam bentuk tabarru' pada permulaannya dan bertukar kepada mu'wadah pada akhirnya.

Prinsip mu'awadah adalah amat fleksible dan ianya hanya bergantung kepada konsep kerelaan bebas dan kesepakatan di antara pihak-pihak yang terlibat. Sebab itu ia juga dikenali sebagai kontrak rida' $i$ yang hanya bergantung kepada kewujudan kerelaan hati tanpa memerlukan kepada bentuk dan upacara tertentu.

\section{Penutup}

Kontrak jual beli matawang asing jelas wujud dalam urusniaga internet. Kontrak yang digunapakai dalam urusniaga matawang asing adalah kontrak bertulis. Kontrak bertulis adalah salah satu dari empat jenis kontrak jual beli yang diharuskan oleh syarak selain dari kontrak secara perbuatan, berlafaz dan isyarat. Pendapat ulama' fiqh bahawa kontrak secara bertulis oleh kedua pihak yang tidak hadir (ghaib) adalah sama seperti kontrak yang dilafazkan oleh kedua orang yang hadir. Apa yang penting dalam kontrak jual beli ialah lahirnya kehendak bagi kedua belah pihak dan bukan lahir dengan cara paksaan.

Walaupun urusniaga ini dinamakan urusniaga hadapan tetapi sebenarnya adalah muwa'adah (perjanjian) iaitu; urusniaga pertukaran berdasarkan harga hadapan yang telah dijanjikan terlebih dahulu dan penyerahan matawang juga berlaku pada tarikh akan datang. Muwa'adah hanyalah persetujuan untuk mengadakan urusniaga al-Sarf pada masa tertentu dan pertukaran barangan pada masa itu. Oleh itu persetujuan itu adalah perjanjian semata-mata dan bukan suatu kontrak jual beli.

Aplikasi hedging atau lindung nilai hanya dibenarkan untuk meminimumkan kerugian atau risiko yang bakal berlaku. Selain itu, leveraj dalam urusniaga matawang asing melalui internet berbeza dengan konsep leveraj dalam pinjaman.

Berdasarkan perbincangan di atas, disimpulkan bahawa pendapat yang paling kuat mengenai pertukaran matawang ialah pendapat dari majoriti ulama' yang mengatakan pertukaran matawang asing dibenarkan dan mestilah berlandaskan syarat-syarat al-Sarf. Urusniaga yang tidak mematuhi syarat tersebut boleh menyebabkan urusniaga tersebut tidak sah atau batal.

Selanjutnya, dicadangkan agar penubuhan Majlis Penasihat Syariah di platform urusniaga matawang asing melalui internet perlu diusahakan. Urusniaga ini semakin popular di kalangan umat Islam. Selain itu disarankan juga satu usaha untuk mewujudnya satu platform yang dikendalikan oleh broker Islam dan mempunyai kerjasama dengan bank negara, agar aktiviti pertukaran matawang asing berlandaskan undangundang transaksi muamalat Islam dapat dilaksanakan mengikut maqasid Syariyyah.

\section{Bibliografi}


Alias Bin Azhar, Mohd Zaki Zainol and Mohd. Nizho Abdul Rahman, 'Kontrak Tukaran Matawang Asing Melalui Internet: Satu Tinjauan Hukum', ISSN 2229-984X', UUMJLS, vol. 6, no. 1, 2015, pp. 137-146

1. Ahmad Jazlan Mat Jusoh, Zamzuri Zakaria (2009), Persoalan Fiqh Dalam Perlaksanaan EDagang dalam Prosiding Seminar Muamalat, Ekonomi dan Kewangan Islam, Selangor: Bangi UKM.

2. Ahmad Hassan (2005), Mata Wang Islam, Terj: Saifurrahman, Jakarta : PT RajaGrfindo Persada.

3. Ahmad Shalabyy, Dr (1996), Khaifa Taktub Bahsan wa Risalah: Dirasah Manhajiyyan, Kaherah : Maktabah al-Nahdhah al-Misri.

4. A.J., Dawson, (1993)“The Internasionalization of Retailing” dalam Retail Change Contemporary Issues diedit oleh Bromley R.D.F dan Thomas C.J, UCL, London: Press Limited

5. Wan Mansor Wan Mahmood (1993), Urusniaga Pasaran Matawang Asing, Kuala Lumpur : Dewan Bahasa dan Pustaka.

6. (1997), Urusniaga Matawang Asing, Kuala Lumpur : Dewan Bahasa dan Pustaka.

7. Ibnu Abidin, Muhammad (1966), Hasyiyah Radd al-Mukhtar ala al-Durr al-Mukhtar, Juz 5, Cetakan 2, Kaherah : Maktabah wa Matbaah Mustafa al-Baabi al-Halabi.

8. Ibnu Human, Kamal al-Din Muhammad ibn Abd al-Wahid,( t.t), Fath al-Qadir, Mesir : Matba'ah Mustafa Muhammad.

9. Asyaf Wajdi Dusuqi (2009), Mekanisme Swap dalam Lindung Nilai, Prosiding Muzakarah Cendekiawan Syariah Nusantara ke-3 Indonesia, ISRA

10. Mohd Zamerey Abdul Razak(2009),Urusniaga Matawang di Institusi Kewangan : Isu Spot dan qobd(1), Muzakarah Cendekiawan Syariah Nusantara ke-3 Indonesia, ISRA

11. (2010), Leverage Dalam Urus Niaga Mata Wang Asing/Foreign Exchange (Forex): Satu Analisis Dari Perspektif Syariah, Jurnal Muamalat, bil 2, Putrajaya:Jakim

12. Mohidin Yahya(1994), Tukaran Asing dan Pasaran Wang: Teori dan Amalan, Kuala Lumpur: Dewan Bahasa dan Pustaka

13. Sahir Hasan (1985), al-Nuqud wa al-Tawazub al-Iqtishadi, Alexandaria.: Muassasah al-Shabab alJamiah Li al-Thibaah.

14. Sami Hassan Ahmad Hamoud (1976), Tatwir al- 'Amal al-Masrafiyah al-Ma Yattafiq al-Syari'ah al-Islamiyyah, Cetakan .3, Kaherah: Maktabah dar al-Turath.

15. Shalabi, Muhammad Mustafa (1404H/1983), al-Madkhal fi al-Ta'rif bil al-Fiqh al-Islami wa Qawaid al-Milkiyyah wa al-Uqud fih. Beirut : Dar al-Nadhah al-Arabiyyah.

16. Al-Zarqa', Mustafa Ahmad, (1418H/1998), al-Madkhal al-Fiqh al-am. Damsyik: Dar al-Qalam.

17. Al-Sanhuri, Abd Razzak,( t.tt), Masadir al-Haq fil al-Fiqh al-Islami, Beirut : Majma' al-Ilm alArabi al-Islam.

18. Al-Buhuti, Mansur Ibnu Yunus Ibn Idris, (1982), Kasyf al-Qina' 'an Matan al-Iqna',juz 3, Lubnan: Dar al-Fikr.

19. Joni Tamkin Borhan, Mohd Yahya Mohd Hussin (2009), Analisis Perkembangan Pasaran Saham Islam di Malaysia, Jurnal Syariah, Jil. 17, Bil. 3 , APIUM

20. Mat Noor Mat Zain (2009)

21. Al-Maltawi, Muhammad bin

Ahmad (1983), Fiqh al-Muamalat ala Mazhab al-Imam Malik, Kaherah: Dar Fikr al-Islami

22. http://en.wikipedia.org/wiki/Foreign_exchange_market, diakses pada 6 Februari 2013 
Alias Bin Azhar, Mohd Zaki Zainol and Mohd. Nizho Abdul Rahman, 'Kontrak Tukaran Matawang Asing Melalui Internet: Satu Tinjauan Hukum', ISSN 2229-984X', UUMJLS, vol. 6, no. 1, 2015, pp. 137-146

23. http://en.wikipedia.org/wiki/Foreign_exchange_spot_trading diakses pada 8 Februari 2013

24. www.belajarforex.com, di akses pada 10 Februari 2013

25. www.bis.org/press/p071219.htm, dilayari pada 6 Februari 2013

26. www.fxdd.com

27. www.gainscope.com

28. www.instaforex.com

29. www.instaforex.my

30. www.islamic finance.net. Mohammed Obaidullah (1993)Diakses pada 24 Januari 2013

31. www.kuasaforex.com

32. www.mafiaforex.com/id/2011/03/definisi-nfa/

33. www.marketiva.com

34. www.nfa.futures.org/basicnet/SearchResults.aspx?type=firm\&firm=FXDIRECTDEALER

35. www.wssfx.com/en/brokers.php, dilayari pada 20 Januari 2013 